\title{
Revista
}

(Ropp) Gestão \& Políticas Públicas

Artigo

\section{A Convergência às Normas Internacionais de Contabilidade Aplicadas ao Setor Público e seu Impacto nos Municípios do Alto Uruguai Gaúcho}

\author{
Convergence to International Financial Reporting Standards Applied to the Public \\ Sector and its Impact in the municipalities of Alto Uruguay Gaucho
}

\section{Convergencia a Normas Internacionales de Información Financiera Aplicada al Sector Público y su impacto en los municipios de Alto Uruguay Gaucho}

\author{
Jhonatan Munaretto Imlau ${ }^{1}$, Fabiano Domingos Bernardo², Daniel Imlau ${ }^{3}$, Cláudia \\ Deboni. ${ }^{4}$
}

1 Filiação institucional. Possui graduação em Ciências Contábeis pela Universidade Comunitária da Região de Chapecó (2008). Pós Graduação em Contabilidade e Controladoria (2010). Mestrando em Contabilidade pela Universidade Federal de Santa Catarina, Santa Catarina, SC, Brasil.

Correspondência: $\quad$ E-mail: jhonatanimlau@gmail.com

2 Filiação institucional. Possui graduação em Ciências Contábeis pela Universidade Federal de Santa Catarina (2010), especialização em Gestão Pública pela Universidade Candido Mendes (2011) e mestrado em Contabilidade pela Universidade Federal de Santa Catarina (2014). Atualmente é Professor Substituto da Universidade Federal de Santa Catarina, Professor Pesquisador do Instituto Federal de Educação, Ciência e Tecnologia de Santa Catarina, Professor Graduação da Faculdade Energia de Administração e Negócios, Professor - Curso Preparatório para Concursos da Escola de Carreira Pública e Analista Administrativo - Contador do Departamento Nacional de Infraestrutura de Transportes.

Correspondência: $\quad$ E-mail: profabianobernardo@gmail.com

3 Filiação institucional. Possui Graduação em Ciências Contábeis pela Universidade Comunitária da Região de Chapecó (1998), é Mestre em Auditoria e Gestão pela Universidade Politécnica e Artística do Paraguai (UPAP) (2010), com o tema de pesquisa: Planejamento Estratégico Participativo e Integrado (PEPI): uma proposta para a gestão eficaz do setor público. Possui Pós-Graduação em Gestão Estratégica de Custos e Controladoria e Contabilidade e Gestão Pública. Atualmente é professor universitário da UCEFF Faculdades atuando na Pós-Graduação. Fundador e Sócio Administrador da Empresa Assessortec Contabilidade e Consultoria desde 1992. 
Correspondência: $\quad$ E-mail: daniel.imlau@hotmail.com

${ }^{4}$ Filiação institucional. Possui graduação em Direito pela Universidade Regional Integrada do Alto Uruguai e das Missões (2013). Atualmente é professor da Escola de Idiomas CCAA Erechim. Tem experiência na área de direito constitucional e internacional, atuando principalmente nos seguintes temas: soberania, normas jurídicas e normas supraconstitucionais.

Resumo

A globalização representa um fato concreto na sociedade e o mundo age em sintonia com os países que o integram. Diante desse contexto global, a padronização dos métodos e conceitos nas diversas áreas, dentre elas, a área pública se torna inevitável. O objetivo central do estudo é identificar o impacto percebido pelos contadores públicos da região do Alto Uruguai do Rio Grande do Sul em face da convergência das Normas Brasileiras de Contabilidade Aplicadas ao Setor Público aos padrões internacionais. O método utilizado foi $\mathrm{O}$ indutivo devido ao estudo de uma base menor procedendo-se à generalização. A pesquisa caracteriza-se como descritiva quanto aos objetivos, de levantamento em relação aos procedimentos, de investigação e de abordagem qualitativa e quantitativa quanto ao problema. Os resultados obtidos apontam uma inteiração razoável dos contabilistas pesquisados frente à adoção das novas normas, sendo que os mesmos preveem a ocorrência de entraves na aplicação, fato este proporcional ao relevante interesse dos mesmos em frequentar cursos de especialização para entendimento e aprofundamento do assunto. Os resultados do estudo permitem concluir que os respondentes estimam um custo razoável para aplicação das normas e que a implantação desta, auxiliará pouco o combate à corrupção.

Palavras-chaves: Normas Internacionais de Contabilidade; Contabilidade Aplicada ao Setor Público; Normas Brasileiras de 
Contabilidade Aplicadas ao Setor Público; Convergência às Normas Internacionais de Contabilidade Pública.

Abstract Globalization is a concrete fact in society and the world acts in line with the countries within it. Given this global context, the standardization of methods and concepts in different areas, among them the public area becomes inevitable. The central objective of the study is to identify the impact perceived by public accountants of Alto Uruguai region of Rio Grande do Sul in the face of convergence of the Brazilian Accounting Standards for Public Sector Entities to international standards. The method used was inductive study due to a smaller base proceeding to the generalization. The research is characterized as descriptive for the goals, survey research regarding the procedures, research and qualitative and quantitative approach to the problem. The results points to a reasonable interaction of the accountants surveyed across the adoption of new standards, and they predict the occurrence of barriers in implementation, a fact proportional to their interest in attending specialization courses for understanding and deepening of the subject. The results of the study allow us to conclude that the respondents estimate a reasonable cost for implementation of the standards and the implementation will assist a little the fight against corruption.

Keywords: International Accounting Standards; Accounting for Public Sector Entities; Brazilian Accounting Standards for Public Sector Entities; Convergence with International Public Accounting Standards.

\section{Resumen}

La globalización es un hecho en la sociedad y el mundo actúa de acuerdo con los países que la componen. Dado este contexto global, la estandarización de los métodos y conceptos en varias áreas, entre ellas la zona pública se convierte en inevitable. El principal objetivo del estudio es identificar el impacto que sienten los contadores públicos del Alto Uruguay Rio Grande do Sul, en la región frente a la convergencia de las Normas de Contabilidad Aplicada de Brasil al 
Sector Público a las normas internacionales. El método utilizado fue el estudio inductivo debido a un procedimiento de base más pequeña a la generalización. La investigación se caracteriza por ser descriptiva de los objetivos, el levantamiento en relación con los procedimientos, la investigación y el enfoque cualitativo y cuantitativo para el problema. Los resultados sugieren una complementariedad razonable de los contadores encuestados antes de la adopción de las nuevas normas, y que predicen la aparición de barreras en la aplicación, lo proporcional al interés relevante de los mismos en la asistencia a cursos especializados para la comprensión y la profundización del tema. Los resultados del estudio apoyan la conclusión de que los encuestados estiman un costo razonable para la aplicación de las normas y el despliegue de esto, poco ayudará a la lucha contra la corrupción.

Palabras Clave: Normas Internacionales de Contabilidad; Aplicado a la Contabilidad del Sector Público; Normas Internacionales de Contabilidad Aplicada al Sector Público; La convergencia de las Normas Internacionales de Contabilidad Pública. 


\section{Introdução}

Tendo em vista a necessidade de adaptações à economia mundial globalizada, as diversas áreas da Contabilidade brasileira têm passado por significativas transformações ao decorrer dos últimos anos no sentido de se adequarem e convergirem aos padrões e procedimentos internacionais.

É importante destacar também que essas modificações afetam de forma direta a Contabilidade Aplicada ao Setor Público. Embora no Brasil, possivelmente atua-se de forma eficaz na mensuração dos atos e fatos relativos ao controle da execução orçamentária, financeira e patrimonial, muitas mudanças são necessárias no intuito de evidenciar, de forma mais concisa, o patrimônio público e ainda acompanhar de maneira correta a utilização dos recursos públicos (CONSELHO FEDERAL DE CONTABILIDADE, 2008).

Partindo dessa necessidade de buscar uma melhor evidenciação dos fenômenos patrimoniais, tornou-se necessária a elaboração de normas que padronizassem os registros contábeis na entidade pública aos padrões internacionais.

Diante desse cenário, são editadas pelo Conselho Federal de Contabilidade (CFC) as Normas Brasileiras de Contabilidade Aplicadas ao Setor Público. As NBCTs 16, como são denominadas, contribuem para a uniformização dos procedimentos e práticas contábeis em convergência aos padrões internacionais, buscando atender de forma transparente a ampla e diversa estrutura pública brasileira.

A aplicação destas normas pode e deve servir como forma de fornecer uma maior transparência às contas públicas, por meio de informações mais confiáveis e controles mais eficientes. E nesse sentido, contribuir para que os cidadãos tenham uma administração com maior responsabilidade de gestão, fatores que têm sido frequentemente demandados pela sociedade em virtude de constantes escândalos de corrupção ligados à entidade pública.

Assim sendo, a aplicabilidade das normas tende a exigir constantemente do profissional contábil a capacidade de quebrar paradigmas e costumes já enraizados na administração pública, bem como buscar atualização profissional constante para se adaptar e acompanhar as modificações estipuladas pela globalização.

Portanto, dada a necessidade da convergência da Contabilidade Aplicada ao Setor Público aos padrões internacionais torna-se importante conhecer e compreender a percepção dos contadores públicos quanto ao impacto que a adoção das medidas dispostas implicará na contabilidade das prefeituras brasileiras. 
Desta forma, o presente estudo, busca responder a seguinte questão de pesquisa: Qual a percepção dos contadores públicos municipais das prefeituras da Região do Alto Uruguai do Rio Grande do Sul quanto à convergência das normas internacionais de contabilidade aplicadas ao setor público?

Com o intuito de responder esta questão, tem-se como objetivo de estudo evidenciar a percepção dos contadores municipais quanto à convergência das normas internacionais de contabilidade aplicadas ao setor público na Região do Alto Uruguai do Rio Grande do Sul.

Além dessa seção introdutória, o presente trabalho abordará os procedimentos metodológicos na seção 2; o referencial teórico na seção 3 e 4; a apresentação e análise dos resultados na seção 5; as considerações finais na seção 6 e por fim as referências utilizadas.

\section{Procedimentos Metodológicos}

A correta utilização dos métodos e técnicas de pesquisas são elementos fundamentais para atingir o objetivo do estudo. Para isso, é necessário acumular todos os dados confrontados, evidências, conhecimentos e informações coletadas a respeito do assunto. Segundo Beuren (2004), considerando as especificidades da Ciência Contábil, as tipologias de pesquisa podem ser definidas como "pesquisa quanto aos procedimentos, quanto aos objetivos e quanto à abordagem do problema".

O estudo em questão trata dos objetivos como pesquisa descritiva, utilizando técnicas padronizadas de coleta de dados como principal característica. Quanto aos procedimentos, caracteriza-se como pesquisa de levantamento pela interrogação direta dos profissionais da área contábil, mediante análise qualitativa e quantitativa, a fim de apontar conclusões a respeito dos dados obtidos. Em relação ao problema abordado, define-se como pesquisa qualitativa e quantitativa, com quantificação tanto na coleta quanto no tratamento das informações.

Os procedimentos de coleta e análise de dados foram realizados com a utilização de questionário elaborado com uma série de quatorze questões, sendo dez fechadas e quatro abertas, respondidas sem a presença do pesquisador, no período de março a junho de 2011. Inicialmente foram encaminhados os questionários por correio eletrônico aos contadores das 32 prefeituras de municípios pertencentes à microrregião do Alto Uruguai, formada por 32 municípios, localizados ao norte do Rio Grande do Sul, sendo que da amostra inicial retornaram para análise as respostas de 22 respondentes. A 
interpretação e a verificação dos dados coletados foram realizadas observando as tabelas e as técnicas de análise descritiva.

\section{A Contabilidade Aplicada ao Setor Público}

A gestão pública possui características próprias que a diferencia das demais entidades, demandando procedimentos contábeis específicos, sendo assim define-se como uma ramificação da Ciência Contábil, cujo principal, de acordo com a Resolução CFC N ${ }^{\circ} 1.128 / 08$, é fornecer aos usuários informações sobre os resultados alcançados e os aspectos de natureza orçamentária, econômica, financeira e física do patrimônio da entidade do setor público e suas mutações, em apoio ao processo de tomada de decisão; a adequada prestação de contas; e o necessário suporte para a instrumentalização do controle social.

De acordo com Kohama (2010, p. 25):

Entende-se, nos tempos atuais, a Contabilidade como uma técnica capaz de produzir, com oportunidade e fidedignidade, relatórios que sirvam à administração no processo de tomada de decisões e de controle de seus atos, demonstrando, por fim, os efeitos produzidos por esses atos de gestão no patrimônio da entidade.

Assim, a aplicação da Contabilidade no Setor Público oferece à seus gestores e a sociedade uma ferramenta importante e objetiva para fornecer informações compreensíveis e confiáveis, necessárias para a prestação de contas e a tomada de decisões.

Carvalho (2010, p. 195), define como objetivo principal da Contabilidade Aplicada ao Setor Público, o de "fornecer aos usuários informações sobre os resultados alcançados e os aspectos de natureza orçamentária, econômica e financeira e física do patrimônio da entidade do setor público e suas mutações."

Por se tratar de um dos ramos mais complexos da ciência contábil, a Contabilidade Pública está presente nos três níveis de direito público interno, são estes: União, Estados, Distrito Federal e Municípios, além de respectivas autarquias e fundações.

De forma a atender a legislação e as relativas normas contábeis, a atuação da contabilidade nas entidades destes setores é estruturada em subsistemas conforme o Manual de Contabilidade Aplicada ao Setor Público (MCASP), editado pela Secretaria do Tesouro Nacional (STN), 2012, p. 13.

Subsistema de Informações Orçamentárias: Registra, processa e evidencia os atos e os fatos relacionados ao planejamento e à execução orçamentária, tais 
como: Orçamento; Programação e execução orçamentária; Alterações orçamentárias; e Resultado orçamentário.

Sistema de Informações Patrimoniais: Registra, processa e evidencia os fatos financeiros e não financeiros relacionados com as variações do patrimônio público, subsidiando a administração pública com informações tais como: Alterações nos elementos patrimoniais; Resultado econômico; e Resultado nominal.

Subsistema de Custos: Registra, processa e evidencia os custos da gestão dos recursos e do patrimônio públicos, subsidiando a administração com informações tais como: Custo dos programas, dos projetos e das atividades desenvolvidas; Bom uso dos recursos públicos; e Custos das unidades contábeis.

Subsistema de Compensação: Registra, processa e evidencia os atos e fatos de gestão cujos efeitos possam produzir modificações no patrimônio da entidade do setor público, bem como aqueles com funções específicas de controle, subsidiando a administração com informações tais como: Alterações potenciais nos elementos patrimoniais; e Acordos, garantias e responsabilidades.

Analisados esses conceitos, é possível afirmar que os subsistemas desempenham um papel fundamental quanto ao controle e a interpretação dos dados contábeis, pois diante destes métodos, torna-se possível prever e fixar no orçamento a receita e a despesa, além de confrontá-las entre a previsão e realização, controlar as operações de crédito, as dívidas ativas, créditos, obrigações, entre outras contas, de forma a revelar as variações patrimoniais ocorridas em um determinado período.

Assim, a estruturação dos subsistemas citados organiza-se de forma a evidenciar os fenômenos que ocorrem no Patrimônio Público, este que, por sua vez, é objeto de estudo da contabilidade pública e pode ser definido como o conjunto de bens e direitos, tangíveis e intangíveis.

\section{Principais mudanças introduzidas pelas Normas Brasileiras de}

\section{Contabilidade Aplicadas ao Setor Público (NBCASP)}

A aplicação da Contabilidade no Setor Público é uma ferramenta fundamental para sociedade, no que se refere à cidadania, pois esta ramificação da Ciência Contábil trata principalmente de controlar e acompanhar as ações e políticas públicas (CONSELHO FEDERAL DE CONTABILIDADE, 2008)

Dessa forma, no sentido de aprimorar as práticas e procedimentos contábeis, o Conselho Federal de Contabilidade contribuiu com a edição de onze normas, denominadas Normas Brasileiras de Contabilidade Aplicadas ao Setor 
Público, as quais se fazem amplamente necessárias devido à complexidade e à dimensão da estrutura da Administração Pública Brasileira.

Tratando-se da Resolução no 128 à 132 do Conselho Federal de Contabilidade de 2008, o Quadro 1 lista as cinco primeiras NBCTs, suas intitulações e disposições gerais, bem como a comparação das principais alterações sofridas após a Portaria 184/08:

\section{Quadro 1. Normas Brasileiras de Contabilidade Aplicadas ao Setor Público.}

\begin{tabular}{|c|c|}
\hline \multicolumn{2}{|l|}{\begin{tabular}{l|l} 
NBC T & INTITULAÇAO \\
Antes da Portaria $184 / 08$
\end{tabular}} \\
\hline Antes da Portaria 184/08 & Após a Portaria 184/ \\
\hline \multicolumn{2}{|c|}{ Conceituação, Objeto e Campo de Aplicação. } \\
\hline $\begin{array}{l}\text { A Contabilidade Pública era uma } \\
\text { ciência própria. }\end{array}$ & $\begin{array}{l}\text { A Contabilidade Pública } \\
\text { ramo da Ciência Contábil } \\
\text { Aplicada ao Setor Público }\end{array}$ \\
\hline $\begin{array}{l}\text { O objeto da Contabilidade Pública era } \\
\text { o orçamento. }\end{array}$ & $\begin{array}{l}\text { O objeto da CASP passa a ser } 0 \\
\text { Patrimônio. }\end{array}$ \\
\hline $\begin{array}{l}\text { Estava Limitada a União, Estados } \\
\text { Municípios e Distrito Federal. }\end{array}$ & $\begin{array}{l}\text { O Campo de aplicação passa a incluir as } \\
\text { empresas estatais dependentes. }\end{array}$ \\
\hline A Contabilidade era centralizada. & $\begin{array}{l}\text { ntábil e } \\
\text { possui pat }\end{array}$ \\
\hline facultativa. & de da cc \\
\hline \multicolumn{2}{|c|}{ Patrimônio e Sistemas Contábeis. } \\
\hline $\begin{array}{l}\text { A estrutura era de apenas dois } \\
\text { grupos: Ativo e Passivo (O Patrimônio } \\
\text { Líquido pertencia ao Passivo) }\end{array}$ & $\begin{array}{l}\text { patrimor } \\
\text { três grup } \\
\text { Líquido. }\end{array}$ \\
\hline $\begin{array}{l}\text { Os subsistemas contábeis eram: } \\
\text { orçamentário, financeiro, patrimonial } \\
\text { e compensado. }\end{array}$ & $\begin{array}{l}\text { temas passam a ser: } \\
\text { io, patrimonial, de custos e } \\
\text { sação. }\end{array}$ \\
\hline \multicolumn{2}{|c|}{ Planejamento e seus instrumentos sob o Enfoque Contábil. } \\
\hline $\begin{array}{l}\text { A avaliação da gestão pública era } \\
\text { realizada pela eficiência. }\end{array}$ & $\begin{array}{l}\text { assa a } \\
\text { e, efic }\end{array}$ \\
\hline $\begin{array}{l}\text { O planejamento era efetuado apenas } \\
\text { por objetos e metas. }\end{array}$ & $\begin{array}{l}\text { nto passa a } \\
\text { dologia, pra }\end{array}$ \\
\hline $\begin{array}{l}\text { O planejamento se dava apenas nos } \\
\text { níveis táticos e operacionais. }\end{array}$ & $\begin{array}{l}\text { nto passa a utilizar dos } \\
\text { gico, tático e operacional. }\end{array}$ \\
\hline \multicolumn{2}{|c|}{ Transações no Setor Público. } \\
\hline \multirow{2}{*}{$\begin{array}{l}\text { As alterações eram apenas } \\
\text { qualitativas ou quantitativas e }\end{array}$} & \\
\hline & alterações \\
\hline \multirow{2}{*}{$\begin{array}{l}\text { qualitativas ou quantitativas e } \\
\text { obedeciam ao regime misto de } \\
\text { competência ou de caixa. (caixa para }\end{array}$} & ou \\
\hline & Líquido \\
\hline $\begin{array}{l}\text { as receitas e competência para as } \\
\text { despesas) }\end{array}$ & \\
\hline & \\
\hline
\end{tabular}




\begin{tabular}{|l|l|}
\hline $\begin{array}{l}\text { Os registros contábeis eram } \\
\text { realizados por meios físicos. }\end{array}$ & $\begin{array}{l}\text { Os registros contábeis passam a serem } \\
\text { previstos por meio eletrônico. }\end{array}$ \\
\hline $\begin{array}{l}\text { Os balanços apresentavam apenas o } \\
\text { exercício atual. }\end{array}$ & $\begin{array}{l}\text { Os balanços passam a demonstrar o } \\
\text { exercício atual e o anterior, permitindo } \\
\text { a comparabilidade. }\end{array}$ \\
\hline $\begin{array}{l}\text { Não havia previsão das notas } \\
\text { explicativas. }\end{array}$ & $\begin{array}{l}\text { Previsão das notas explicativas, que } \\
\text { devem fornecer um detalhamento mais } \\
\text { completo e simplificado. }\end{array}$ \\
\hline $\begin{array}{l}\text { O controle interno exercia apenas } \\
\text { atividades administrativas. }\end{array}$ & $\begin{array}{l}\text { O controle interno passa a ter } \\
\text { responsabilidade sobre a confiabilidade } \\
\text { dos dados. }\end{array}$ \\
\hline $\begin{array}{l}\text { A contabilidade pública não possuía } \\
\text { manual. }\end{array}$ & $\begin{array}{l}\text { A CASP, passa a possuir um manual. (O } \\
\text { MCASP). }\end{array}$ \\
\hline $\begin{array}{l}\text { A escrituração era prevista apenas } \\
\text { por meio de registros físicos. }\end{array}$ & $\begin{array}{l}\text { Passa a ser prevista a digitalização dos } \\
\text { registros físicos. }\end{array}$ \\
\hline
\end{tabular}

Fonte: Elaborado pelo autor.

Considerando o Quadro 1, que trata das normas um à cinco, pode-se observar que as normas em questão tem como objetivo: estabelecer, conceitos, objeto e campo de aplicação; conceituar, classificar e estruturar o patrimônio público; expressar em planos hierarquicamente ligados as bases para controle contábil; estabelecer conceitos, natureza e tipicidade das transações; e estabelecer critérios para o registro contábil.

Em adição as NBCTs 16, o Quadro 2 dispõe de forma detalhada as normas 16.6 à 16.10, bem como suas alterações decorrentes da Portaria 184/08:

\section{Quadro 2. Normas Brasileiras de Contabilidade Aplicadas ao Setor Público.}

\begin{tabular}{|c|c|}
\hline INTITULAÇÃO & \\
\hline \multicolumn{2}{|l|}{ Antes da Portaria 184/08 } \\
\hline Demonstrações Contábe & \\
\hline $\begin{array}{l}\text { Não era prevista a atualização de } \\
\text { valores. }\end{array}$ & $\begin{array}{l}\text { Mediante a depreciação, exaustão e } \\
\text { reavaliação, os bens e obrigações não } \\
\text { financeiros são atualizados e seus } \\
\text { valores tornam-se conversíveis em } \\
\text { moeda. }\end{array}$ \\
\hline Não existiam limites de escrituração. & $\begin{array}{l}\text { As designações genéricas não podem } \\
\text { ultrapassar o limite de } 10 \% \text { do total do } \\
\text { grupo de contas. }\end{array}$ \\
\hline $\begin{array}{l}\text { A Demonstração do Fluxo de Caixa } \\
\text { não era obrigatória. }\end{array}$ & $\begin{array}{l}\text { A DFC passa a ser obrigatória podendo- } \\
\text { se optar pelo método direto ou indireto. }\end{array}$ \\
\hline $\begin{array}{l}\text { O rol das demonstrações contábeis } \\
\text { que era formado por Balanço } \\
\text { Orçamentário, Balanço Financeiro, } \\
\text { Balanço Patrimonial e Demonstração } \\
\text { das Variações Patrimoniais. }\end{array}$ & 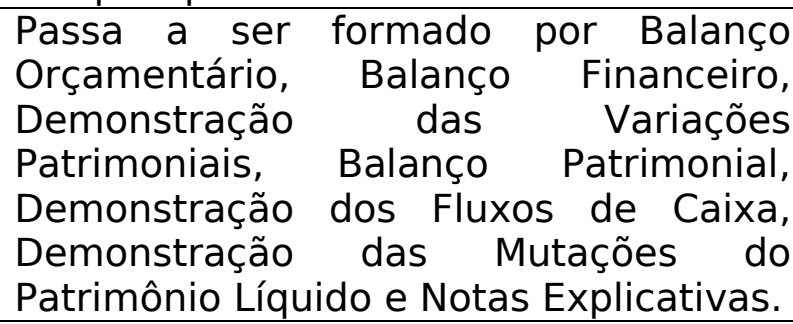 \\
\hline
\end{tabular}




\begin{tabular}{|c|c|}
\hline $\begin{array}{l}\text { Os lançamentos eram efetuados pelo } \\
\text { valor líquido, sendo que não havia } \\
\text { transparência quanto às deduções } \\
\text { concedidas. }\end{array}$ & $\begin{array}{l}\text { Contas redutoras conhecidas como } \\
\text { grupo } 09 \text {, passam a serem obrigatórias, } \\
\text { permitindo inclusive a identificar } \\
\text { possíveis renuncias de receitas. }\end{array}$ \\
\hline $16.7 \quad$ Consolidação das Demon & strações Contábeis. \\
\hline $\begin{array}{llr}\text { Não havia } & \text { obrigatoriedade da } \\
\text { consolidação } & \text { das demonstrações } \\
\text { contábeis. } & & \end{array}$ & $\begin{array}{l}\text { A consolidação das demonstrações } \\
\text { contábeis, passa a ser obrigatória, } \\
\text { facilitando a visão global do resultado e } \\
\text { o controle social. }\end{array}$ \\
\hline $\begin{array}{l}\text { Não havia distinção nem conceito } \\
\text { das categorias. }\end{array}$ & $\begin{array}{l}\text { Duas novas categorias de consolidação } \\
\text { são criadas: dependência orçamentária } \\
\text { e regimental. }\end{array}$ \\
\hline Controle Interno. & \\
\hline $\begin{array}{l}\text { A posição do profissional contábil no } \\
\text { controle interno não era clara. }\end{array}$ & $\begin{array}{l}\text { Passa a ser evidenciada a necessidade } \\
\text { do profissional contábil no controle } \\
\text { interno. }\end{array}$ \\
\hline $\begin{array}{l}\text { As normas eram ap } \\
\text { geral. }\end{array}$ & $\begin{array}{l}\text { É definida a estrutura e funcionalidade } \\
\text { do controle interno como diretriz de } \\
\text { manuais de procedimento. }\end{array}$ \\
\hline Depreciação, amortizaçã & o e exaustão. \\
\hline $\begin{array}{l}\text { Apenas as autarquias estavam } \\
\text { obrigadas a mensurar depreciação, } \\
\text { amortização e exaustão, as demais } \\
\text { entidades estavam facultadas. }\end{array}$ & $\begin{array}{l}\text { A mensuração da Depreciação, } \\
\text { amortização e exaustão, passam a } \\
\text { serem obrigatórias para todas as } \\
\text { entidades sujeitas a CASP. }\end{array}$ \\
\hline $\begin{array}{l}\text { Não havia normas e critérios para a } \\
\text { operacionalização, nem mesmo nas } \\
\text { autarquias obrigadas. }\end{array}$ & $\begin{array}{l}\text { Foram definidos os principais critérios e } \\
\text { normas para a operacionalização da } \\
\text { depreciação, amortização e exaustão. }\end{array}$ \\
\hline $\begin{array}{l}\text { Avaliação e Mensuração } \\
\text { do Setor Público. }\end{array}$ & de Ativos e Passivos em Entidades \\
\hline $\begin{array}{l}\text { A avaliação e mensuração eram } \\
\text { facultativas para todas as entidades. }\end{array}$ & $\begin{array}{l}\text { A avaliação e mensuração de ativos e } \\
\text { passivos passam a ser obrigatórias. }\end{array}$ \\
\hline $\begin{array}{l}\text { Não havia normas e critérios para a } \\
\text { operacionalização, nem mesmo nas } \\
\text { autarquias obrigadas. }\end{array}$ & $\begin{array}{l}\text { Foram definidos os principais critérios e } \\
\text { normas para a operacionalização da } \\
\text { avaliação, semelhantes aos da iniciativa } \\
\text { privada. }\end{array}$ \\
\hline
\end{tabular}

Fonte: Elaborado pelo autor.

Em resumo, as disposições gerais da NBCTs 16.6 à 16.10, representadas no quadro 2, tem o propósito principal de estabelecer: as demonstrações contábeis a serem elaboradas e divulgadas; os conceitos, abrangência e procedimentos da consolidação das demonstrações contábeis; as referências para o controle interno; os critérios e procedimentos para o registro da depreciação, amortização e exaustão; e os critérios para a avaliação e a mensuração de ativos e passivos integrantes do patrimônio.

Dessa forma, conforme demonstrado nos quadros 1 e 2 , a aplicação das novas normas tendem a padronizar os registros contábeis, no intuito de possibilitar aos usuários auxílio na tomada de decisões, além de acesso às informações de forma tempestiva e consistente. 
Assim, é possível perceber que as mudanças na contabilidade governamental tendem a uma melhor avaliação dos impactos das políticas públicas e da gestão no que diz respeito às questões fiscais, econômicas e sociais relacionados às variações do patrimônio público.

As transformações decorrentes dessas alterações fornecem à sociedade de forma significativa uma visão mais real e abrangente da situação pública, facilitando a cobrança por uma administração transparente e eficiente, no sentido de propiciar à população a correta destinação dos recursos públicos.

\section{Resultados da Pesquisa}

A aplicação do questionário visou atingir o objetivo do estudo, que é traçar o perfil do contador que atua na área pública, observar as mudanças que as NBCASPs representarão na administração pública, determinar os principais entraves da aplicação, além de investigar o interesse dos contadores quanto à criação de um curso de pós-graduação para o aprofundamento do assunto. As questões efetuadas e os resultados do estudo são apresentados a seguir:

Quadro 3. Qual o seu nível de formação acadêmica?

\begin{tabular}{|l|c|c|}
\hline \multicolumn{1}{|c|}{ Respostas } & $\begin{array}{c}\text { Frequência } \\
\text { Relativa }\end{array}$ & $\begin{array}{c}\text { Frequência } \\
\text { Absoluta }\end{array}$ \\
\hline Técnico & 27 & 6 \\
\hline Graduado & 50 & 11 \\
\hline Pós-Graduado (Especialização) & 18 & 4 \\
\hline Mestre & 5 & 1 \\
\hline Total & 100 & 22 \\
\hline
\end{tabular}

Fonte: Elaborada pelo autor.

Conforme dados do Quadro 3, 50\%, ou seja, a metade dos respondes são graduados em contabilidade e $18 \%$ possuem especialização. Outro nível de formação em destaque são os técnicos em contabilidade, os quais ocupam a segunda posição, representado $27 \%$ dos profissionais entrevistados.

Constata-se que os respondentes do questionário possuem como perfil de formação acadêmica a graduação, e poucos destes buscaram um aperfeiçoamento profissional ou uma especialização. Fato esse, que pode ser observado ao analisarmos que dos 16 profissionais que chegaram ao nível de graduação, apenas 5 prosseguiram na qualificação de sua carreira, sendo que 4 realizaram cursos de especialização e apenas 1 de mestrado. 


\section{Quadro 4. Quantos anos você atua na Contabilidade Aplicada ao Setor Público - CASP?}

\begin{tabular}{|l|c|c|}
\hline \multicolumn{1}{|c|}{ Respostas } & $\begin{array}{c}\text { Frequência } \\
\text { Relativa }\end{array}$ & $\begin{array}{c}\text { Frequência } \\
\text { Absoluta }\end{array}$ \\
\hline Até 05 anos & 14 & 3 \\
\hline Entre 06 e 10 anos & 14 & 3 \\
\hline Entre 11 e 20 anos & 45 & 10 \\
\hline Mais de 20 anos & 27 & 6 \\
\hline Total & 100 & 22 \\
\hline
\end{tabular}

Fonte: Elaborada pelo autor.

De acordo com o Quadro 4, do total dos respondentes $45 \%$ atuam na área contábil entre 11 e 20 anos e outros 27\% possuem experiência na atividade superior a 20 anos. Em segundo plano apareceram os profissionais com menor experiência, sendo entre 06 e 10 anos 14\%, e 5 anos ou menos 14\%.

Os resultados apontam um perfil de contador experiente, pois, dos profissionais analisados, $75 \%$ atuam na área contábil aplicada ao setor público por um tempo superior ao de 10 anos.

\section{Quadro 5. Qual a forma jurídica de atuação?}

\begin{tabular}{|l|c|c|}
\hline \multicolumn{1}{|c|}{ Respostas } & $\begin{array}{c}\text { Frequência } \\
\text { Relativa }\end{array}$ & $\begin{array}{c}\text { Frequência } \\
\text { Absoluta }\end{array}$ \\
\hline Concurso Público & 95 & 21 \\
\hline Cargo em Comissão & 0 & 0 \\
\hline Terceirizado Pessoa Jurídica & 5 & 1 \\
\hline Terceirizado Pessoa Física & 0 & 0 \\
\hline Total & 100 & 22 \\
\hline
\end{tabular}

Fonte: Elaborada pelo autor.

O Quadro 5 indica que praticamente todos os profissionais atuam na área pública pela forma de concurso público, pois $95 \%$ dos respondentes atuam nessa área por meio dessa modalidade, a qual permite selecionar o candidato mais qualificado de forma ampla e democrática.

\section{Quadro 6. Você tem procurado se inteirar nas mudanças que vem ocorrendo no CASP?}

\begin{tabular}{|l|c|c|}
\hline \multicolumn{1}{|c|}{ Respostas } & $\begin{array}{c}\text { Frequência } \\
\text { Relativa }\end{array}$ & $\begin{array}{c}\text { Frequência } \\
\text { Absoluta }\end{array}$ \\
\hline Nem um pouco & 0 & 0 \\
\hline Pouco & 32 & 7 \\
\hline Razoavelmente & 45 & 10 \\
\hline Muito & 23 & 5 \\
\hline
\end{tabular}




\begin{tabular}{|l|c|c|}
\hline Total & 100 & 22 \\
\hline
\end{tabular}

Fonte: Elaborada pelo autor.

Quanto ao interesse dos respondentes em se inteirar nas mudanças que vem ocorrendo na área contábil, o Quadro 6 mostra que $45 \%$ dos profissionais definiram sua inteiração nas mudanças como "razoável", 32\% indicaram "pouco" e $23 \%$ apontaram aprofundar-se "muito" no assunto. No entanto, nenhum respondente definiu não ter procurado se inteirar das mudanças ocorridas.

Conforme Portaria STN $n^{\circ}$ 231/12, a obrigatoriedade para a aplicação das mudanças que dispõe o CASP para os municípios dar-se-á até o ano de 2014. Observando esse prazo, é possível afirmar que muitos dos profissionais ainda devem buscar se aprimorar e se especializar nesse assunto, haja vista que as mudanças são complexas e abrangentes. Além disso, diante da forte fiscalização por parte do Conselho Federal e dos Conselhos Regionais de Contabilidade e Tribunal de Contas da União, as entidades que não se adequarem às mudanças estarão sujeitas a reprovação das Prestações de Contas.

Sendo assim, considerando o prazo de aplicação e as penalizações que as Prestações de Contas poderão ser submetidas em caso de irregularidades, entende-se que a inteiração dos contadores, no momento da aplicação do questionário, apresenta-se abaixo do esperado para um assunto que demanda um amplo conhecimento.

\section{Quadro 7. Em sua opinião o custo a ser despendido pela entidade pública para adequação e adaptação das novas normas será?}

\begin{tabular}{|l|c|c|}
\hline \multicolumn{1}{|c|}{ Respostas } & $\begin{array}{c}\text { Frequência } \\
\text { Relativa }\end{array}$ & $\begin{array}{c}\text { Frequência } \\
\text { Absoluta }\end{array}$ \\
\hline Muito Baixo & 0 & 0 \\
\hline Baixo & 0 & 0 \\
\hline Razoável & 82 & 18 \\
\hline Alto & 18 & 4 \\
\hline Muito Alto & 0 & 0 \\
\hline Total & 100 & 22 \\
\hline
\end{tabular}

Fonte: Elaborada pelo autor.

De acordo com o Quadro 7, verifica-se que os profissionais entrevistados acreditam que o custo a ser despendido pela entidade pública se manterá entre "alto" e "razoável", este ultimo representando um percentual de $82 \%$ da opinião dos respondentes. Não foram obtidas respostas para aqueles que acreditassem que o custo fosse "muito baixo", "baixo" e "muito alto".

O índice pode ser explicado diante da necessidade de qualificação e/ou contratação de profissionais da área de engenharia para fornecer informações e avaliações da situação patrimonial da entidade. 
Diante da complexidade das mudanças na área pública com a implantação das novas normas contábeis, os contadores entendem que existem algumas alterações que não representam importância quanto aos aspectos da transparência e da melhoria de vida da população. Entre essas está a obrigatoriedade de avaliação e mensuração dos ativos e passivos, a reavaliação de estoques, o lançamento dos bens de uso público, a alteração dos demonstrativos contábeis e as mudanças nas disposições dos regimes contábeis.

Quanto às alterações consideradas pelos respondentes como as mais importantes para a transparência e a melhoria da qualidade de vida, citem-se a previsão de digitalização dos registros físicos, o registro contábil diante de meios eletrônicos, a valorização dos fatos contábeis na competência, a utilização de notas explicativas que fornecem um detalhamento mais completo e simplificado e a avaliação dos bens patrimoniais.

Quadro 8. Em sua opinião a aplicação das novas normas irá auxiliar o combate a corrupção?

\begin{tabular}{|l|c|c|}
\hline \multicolumn{1}{|c|}{ Respostas } & $\begin{array}{c}\text { Frequência } \\
\text { Relativa }\end{array}$ & $\begin{array}{c}\text { Frequência } \\
\text { Absoluta }\end{array}$ \\
\hline Nem um pouco & 9 & 2 \\
\hline Muito pouco & 50 & 11 \\
\hline Razoavelmente & 36 & 8 \\
\hline Muito & 5 & 1 \\
\hline Total & 100 & 22 \\
\hline
\end{tabular}

Fonte: Elaborada pelo autor.

Diante do Quadro 8, pode-se afirmar que 50\% dos respondentes acreditam que a aplicação das novas normas irá auxiliar "muito pouco" o combate à corrupção; $36 \%$ entendem que o impacto será "razoável"; $5 \%$ responderam que a aplicação irá auxiliar em "muito" na transparência das contas públicas e $9 \%$ acreditam que as novas normas não serão uma ferramenta de transparência.

\section{Quadro 9. Em sua opinião o Profissional Contábil será mais valorizado dentro da organização e da sociedade?}

\begin{tabular}{|l|c|c|}
\hline \multicolumn{1}{|c|}{ Respostas } & $\begin{array}{c}\text { Frequência } \\
\text { Relativa }\end{array}$ & $\begin{array}{c}\text { Frequência } \\
\text { Absoluta }\end{array}$ \\
\hline Nem um pouco & 9 & 2 \\
\hline Muito pouco & 59 & 13 \\
\hline Razoavelmente & 27 & 6 \\
\hline Muito & 5 & 1 \\
\hline Total & 100 & 22 \\
\hline
\end{tabular}

Fonte: Elaborada pelo autor. 
O Quadro 9 evidencia que 59\% dos profissionais pesquisados acreditam que serão valorizados "muito pouco" dentro da organização e da sociedade em relação às novas mudanças da CASP; $27 \%$ consideram o impacto como "razoável"; $9 \%$ entendem que não serão valorizados e apenas $5 \%$ apontam para uma "alta" valorização da classe.

Quadro 10. Você entende que possam ocorrer entraves quanto à implantação das novas normas da CASP?

\begin{tabular}{|l|c|c|}
\hline \multicolumn{1}{|c|}{ Respostas } & $\begin{array}{c}\text { Frequência } \\
\text { Relativa }\end{array}$ & $\begin{array}{c}\text { Frequência } \\
\text { Absoluta }\end{array}$ \\
\hline Sim & 59 & 13 \\
\hline Não & 41 & 9 \\
\hline Total & 100 & 22 \\
\hline
\end{tabular}

Fonte: Elaborada pelo autor.

Conforme dados do Quadro 10, 59\% dos respondentes entendem que poderão ocorrer entraves quanto à implantação das novas normas da CASP. Outros $41 \%$ acreditam que a aplicação das novas normas no setor pode ser realizada sem muitos obstáculos ou dificuldades.

Dentre as dificuldades apontadas como mais relevantes está a baixa instrução dos profissionais, a omissão das entidades representativas, os recursos precários como a internet, sistemas e outras ferramentas, o custo benefício da avaliação patrimonial e a dificuldade de formar um grupo para a tomada de decisões.

Quadro 11. Você recomendaria um curso de pós-graduação com ênfase nas alterações da Contabilidade Aplicada ao Setor Público, e estaria disposto a freqüentá-lo?

\begin{tabular}{|l|c|c|}
\hline \multicolumn{1}{|c|}{ Respostas } & $\begin{array}{c}\text { Frequência } \\
\text { Relativa }\end{array}$ & $\begin{array}{c}\text { Frequência } \\
\text { Absoluta }\end{array}$ \\
\hline $\begin{array}{l}\text { Não recomendaria e não } \\
\text { frequentaria }\end{array}$ & 5 & 1 \\
\hline $\begin{array}{l}\text { Não recomendaria, mas } \\
\text { freqüentaria }\end{array}$ & 0 & 0 \\
\hline $\begin{array}{l}\text { Recomendaria, mas não } \\
\text { freqüentaria }\end{array}$ & 18 & 4 \\
\hline Recomendaria e freqüentaria & 77 & 17 \\
\hline Total & 100 & 22 \\
\hline
\end{tabular}

Fonte: Elaborada pelo autor.

A pesquisa indica, ainda, conforme o Quadro 11, que 95\% dos respondentes recomendam um curso de pós-graduação com ênfase nas alterações ocorridas na Contabilidade Aplicada ao Setor Público e, desses, 77\% 
estariam dispostos a frequentar o curso a fim de se especializar e se aprimorar. Outros 5\% responderam que além de não recomendar tal curso, não o frequentaria.

Constata-se que diante da complexidade e abrangência das mudanças, muitos profissionais apresentam-se interessados em aprofundar seus conhecimentos em curso de especialização. Dentre os temas julgados mais importantes, estão os lançamentos contábeis, custos, reavaliação patrimonial, demonstrações contábeis, lei de diretrizes orçamentárias e o orçamento.

\section{Considerações Finais}

O propósito desse artigo foi evidenciar a percepção dos contadores públicos municipais das prefeituras da Região do Alto Uruguai do Rio Grande do Sul quanto a convergência das normas internacionais de contabilidade aplicadas ao setor público. A partir da pesquisa realizada, conclui-se que os contadores que atuam na área pública dos municípios da região do Alto Uruguai do Rio Grande do Sul, em sua maioria, são graduados, atuam entre 11 e 20 anos na área e são concursados.

Com relação ao interesse pelas inovações, $45 \%$ procuraram se inteirar "razoavelmente" das mudanças que vem ocorrendo na CASP. Quanto aos gastos públicos, $82 \%$ entendem que o custo a ser despendido pela entidade pública para adequação e adaptação das novas normas será "razoável".

Em se tratando de transparência, mais da metade dos respondentes julgam que a aplicação das novas normas não terá grande impacto no combate à corrupção, e com relação à implantação das novas normas, 59\% acreditam que possam ocorrer entraves.

Quanto ao interesse por atualização profissional, dos contadores pesquisados, $77 \%$ recomendariam e freqüentariam um curso de pós-graduação com ênfase nas alterações da CASP.

Portanto, os resultados obtidos indicam vantagens e desvantagens na aplicação das novas normas. A análise geral dos resultados demonstra que os contadores públicos que fizeram parte desta pesquisa possuem em sua grande maioria, vasta experiência na atuação profissional na área pública (mais de dez anos) e, em geral, estão pouco esperançosos quanto a sua valorização profissional a partir da adoção das novas normas, bem como que estas possam contribuir para a diminuição da corrupção no setor público. 


\section{Referências Bibliográficas}

Beuren, Ilse Maria. (2004). Como elaborar os monográficos em contabilidade: teoria e prática. 2. ed. São Paulo: Atlas.

Brasil. Secretaria do Tesouro Nacional. (2012). Manual de contabilidade aplicada ao setor público: volume I - Procedimentos Contábeis Orçamentários. Brasília. $100 \mathrm{p}$.

Brasil. Secretaria do Tesouro Nacional. (2012). Manual de contabilidade aplicada ao setor público: volume II - Procedimentos Contábeis Patrimoniais. Brasília. $125 \mathrm{p}$.

Brasil. Secretaria do Tesouro Nacional. (2012). Manual de contabilidade aplicada ao setor público: volume III - Procedimentos Contábeis Específicos. Brasília. $234 \mathrm{p}$.

Brasil. Secretaria do Tesouro Nacional. (2012). Manual de contabilidade aplicada ao setor público: volume IV- Plano de Contas Aplicado ao Setor Público. Brasília. $130 \mathrm{p}$.

Brasil. Secretaria do Tesouro Nacional. (2012). Manual de contabilidade aplicada ao setor público: volume $V$ - Demonstrações Contábeis Aplicadas ao Setor Público. Brasília. 67 p.

Carvalho, Deusvaldo. (2010). Orçamento e contabilidade pública. 5. ed. São Paulo: Campus.

Conselho Federal de Contabilidade. (1993). Resolução no 750, de 29 de dezembro de 1993.

Conselho Federal De Contabilidade. (2008). Resolução № 1128 à 1137, De 21 De Novembro De 2008. Disponível em: <www.cfc.org.br>.

Conselho Federal De Contabilidade. (2008). Contabilidade Pública: A Convergência aos Padrões Internacionais de Contabilidade como Contribuição Efetiva da Gestão. Brasília.

Costa, Arlindo. (2006). Metodologia científica. Mafra: Nosde.

Kohama, Hélio. (2010). Balanços públicos: Teoria e Prática. 2. ed. São Paulo: Atlas. 
Silva, Lino Martins da. (2009). Contabilidade governamental: Um enfoque Administrativo da Noca Contabilidade Pública. 8. ed. São Paulo: Atlas.

Recebido em 29/06/2014

Aceito 21/10/2014 